\title{
Analysis of Surface Area Fluctuation of the Haramaya Lake using Remote Sensing
} Data

\section{Kbrom Ambachew Gebrehiwot ${ }^{1 *}$, Abebe Fanta Bedie ${ }^{2}$, Mehari Gidey Gebrewahid ${ }^{1}$ and $^{2}$ Birhanu Kindishih Hishe ${ }^{2}$}

${ }^{1}$ Department of Water Resources and Irrigation Engineering, School of Water Technology, Aksum University, P.O. Box 314, Shire-Endaselassie, Ethiopia (*kibe0611@gmail.com).

${ }^{2}$ Institute of Technology, Haramaya University, Haramaya, Ethiopia (fantaalemitu@gmail.com).

\begin{abstract}
Human's unwise and ineffective exploitation behavior has caused losses of the vital natural resources, soil and water, which will definitely leave the future of the next generation in jeopardy. As a result of human intervention and natural causes most lakes in Ethiopia are shrinking in size while others are showing increase in volume. The intensive exploitation, beyond its regeneration rate, of the Lake Haramaya for water supply and agricultural purposes by the community within and outside its catchment boundary has led to its extinction. Although, some studies have been conducted on land use/land cover dynamics, the focus given to quantification of temporal variability lake surface area and the impact of weather variability on the lake water was inadequate. Hence, this study was conducted with the prime objective of mapping/quantifying the temporal lake surface area fluctuation using time series remote sensing images and investigating the impact of weather/climate variability on the lake. After acquiring Landsat images of the years 1985, 1995, 2003, 2010 and 2016 over the dry Haramaya Lake basin (path/row 166/54), the Modified Normalized Difference Water Index (MNDWI) and the Normalized Difference Vegetation Index (NDVI) were used for enhancing and extracting the open water surface of the lake. All of the enhanced images display a trend of decreasing lake surface water area with an average shrinkage of $23.6 \%$ between the year 1985 and up to its disappearance. After 2000 the lake surface area shrinkage was at its maximum which has a direct relation with the occurrence of dry weather as a result of relatively higher temperature and low rainfall between the years 2000 to 2003 .
\end{abstract}

Keywords: Haramaya Lake, Image enhancement, Fluctuation, MNDWI, NDVI, Ethiopia.

\section{INTRODUCTION}

Mankind's activity and his endless effort to win his daily bread, cover his body and protect the same from chilling cold and burning sunlight and provide roof over his head resulted in the disturbance of the environment as a whole and modifications of landscape. These environmental disturbance and modification are largely manifested through measurable land-use and/or landcover alterations. These alterations, in most cases, have a devastating effect on lives and livelihoods of human beings causing misery and suffering that cannot be ignored or underestimated. Above all, the losses of vital natural resources, soil and water, will definitely leave the future of next generation in jeopardy. As a result, we all learnt that we should not turn 
our blind eyes and deaf ears on events that rampantly happening and taking their own uncontrolled road to the future any more. Setegn et al. (2011) indicated that due to human intervention and/or natural causes most lakes in Ethiopia are shrinking in size while others are showing increase in volume. Such land-use and land-cover changes are mainly caused due to expansion of agriculture, unplanned and controlled settlement and grazing and the removal of vegetation. Forestlands, grasslands, wetlands and deserts have been modified, and transformed both in space and time. Size of human settlement, agricultural land and other related land use systems have increased dramatically in decades. Consequently, in the past few decades, conversion of water bodies, grassland, woodland and forestland into cropland and pasture has significantly increased in tropics. Lake Haramaya is not exceptional in this regards; the Lake systematically flared up and died away due to unwise human intervention. Even now, the groundwater of the dried Lake Haramaya catchment is very precious commodity not only for the people of Haramaya Woreda but also for the surrounding towns and Harar region.

Lake Haramaya Watershed, in eastern Ethiopia, has been source of water supply for the three major towns of Harar, Haramaya, and Awoday and Haramaya University (Tadesse et al., 2010). Water from Lake Haramaya, had been in use for irrigation purpose too over the years until it was completely dried (Edo, 2009). This, results in over exploitation of the water resources of the catchment which led to the disappearance of the lake and decline in groundwater storage. Increasing irrigation and domestic water use, changes in the climate and land use/cover are believed to be the causes of Lake Haramaya's demise. Studies made on land use/cover dynamics clearly indicated that aquatic vegetation, urban built-up area, cultivated and rural settlement, forest, grass, open water, marsh and shrub had changed significantly with devastating effect on the Lake Haramaya. However, no attempt has been made to correlate the effect of climatic variability on the lake. Hence, this study was conducted with the prime objective of mapping/quantifying the temporal lake surface area fluctuation using time series remote sensing images and investigating the impact of weather/climate variability on the lake.

\section{MATERIALS AND METHODS}

\subsection{The Study Area}

Lake Haramaya Catchment is one of the catchments in the eastern Ethiopia found in Haramaya District, Eastern Hararghe zone, Oromia Regional state. The catchment is situated on the main 
road from Addis Ababa to Harar town at a distance of $505 \mathrm{~km}$ from Addis Ababa and $20 \mathrm{~km}$ northwest of Harar town. It is situated at $9^{0} 23^{\prime}-9^{0} 26^{\prime}$ North of latitude and $41^{0} 59^{\prime}-42^{0} 02^{\prime}$ East of longitude (Tadesse et al., 2010).

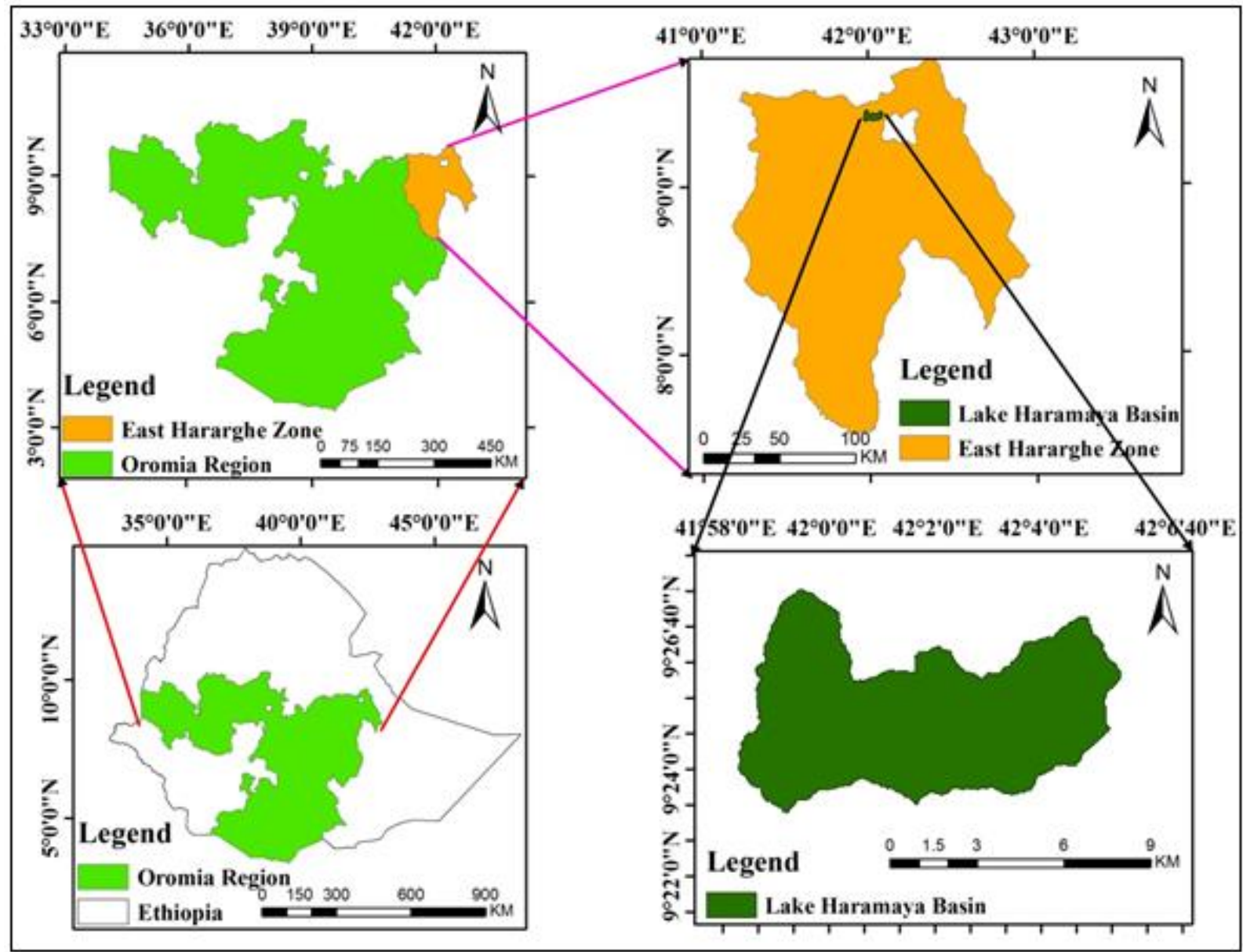

Figure 1. Location map of Haramaya Lake Basin.

The total area of the catchment is 5032 ha and encompasses a small part of Haramaya town, the Haramaya university campus, three peasant associations (Damota, Ifa-Bate, and TijiGebissa) fully, and another two partially, Ifa-Oromia (90\%) and Gubi-Selama (10\%) (Setegn et al., 2011). According to the East-Hararghe zone planning and economic development department, Haramaya District with a total of 18,800 stands fifth after Girawa, Deder, Bedeno, and Meta districts in its population size (Senti et al., 2014). The livelihood of the community in Lake Haramaya catchment is mainly based on mixed farming, that is, cropping and livestock production (Muleta et al., 2006). 
Based on the agro-climatologically classification, Haramaya woreda has Woina Dega (wet and cool, 70\%) and Kolla (dry and hot 30\%) areas. The annual rainfall distribution record indicates that the area receives a bimodal rainfall type with the mean annual precipitation of 751 mm (Alemayehu et al., 2007). According to Muleta et al. (2006), the dry period (less than $30 \mathrm{~mm}$ per month) extends from October to January inclusive; December with $9 \mathrm{~mm}$ is the driest month. The wet season starts in February $(37 \mathrm{~mm})$ and extends up to March $(67 \mathrm{~mm})$. The monthly rainfall is more than $100 \mathrm{~mm}$ from April to September, except June $(65 \mathrm{~mm})$. The wettest month is August with an average rainfall of $144 \mathrm{~mm}$. The maximum and minimum mean annual temperatures for the area are $23.8^{\circ} \mathrm{C}$ and $9.6^{\circ} \mathrm{C}$ respectively (Tadesse et al., 2010). The mean monthly relative humidity before year 2003 falls between 53 and 75\% (Alemayehu et al., 2007).

Lake Haramaya Catchment covers areas with elevation ranging between 1980 and 2343 m.a.s.l. About $71 \%$ of the catchment is characterized by undulating and rolling topography (Muleta et al., 2006). On the basis of USDA soil textural classification scheme, the soil in the watershed was grouped in to four different classes: clay $\left(14.6 \mathrm{~km}^{2}\right)$, clay-loam $\left(25.7 \mathrm{~km}^{2}\right)$, sandy clay loam (6.1 km²) and sandy-loam (5 km²) (Nata Tadesse and Abdulaziz Mohammad, 2009). The six land use types comprised in the study area are cultivated land (78.3\%), grazing land (7.6\%), forest $(0.6 \%)$, settlement $(4.5 \%)$, shrub (4.6\%) and swampy area (4.5\%) (Nata Tadesse and Abdulaziz Mohammad, 2009). The major crops grown in the area under irrigated conditions are chat and vegetables (potato, lettuce, carrot, onion, tomato and cabbage). Sorghum and maize are grown under rain-fed conditions (Setegn et al., 2011).

\subsection{Research Methodology}

Level 1 US Geological Survey (USGS) images from Landsat satellite (Landsat 5 TM, Landsat 7 ETM+ and L8 OLI/TIRS) were the remote sensing data used in this research. These images are in the World Geodetic System (WGS84) datum in GeoTIFF format and projected using the Universal Transverse Mercator system. In total five images, which were acquired over the Haramaya Lake basin (path/row 166/54) on the month of late February and early March for the years 1985, 1995, 2003, 2010 and 2016, were used for the lake surface water mapping analysis.

As there is hardly any time series water surface and water level data of Lake Haramaya, analysis of the water resources assessment depends entirely on the use of remotely sensed imagery. This involves the delineation of open water using thematic information extraction techniques. There are various methods for the extraction of water information from remote 
sensing imagery including the Normalized Difference Vegetation Index (NDVI), the Normalized Difference Water Index (NDWI), and modified Normalized Difference Water Index (MNDWI). TM, ETM+ and OLI/TIRS image supplied different bands spectrum of ground object. Every band corresponds to a certain rang of light wave, water has different reflection characteristics on these bands. So the spectrum value of water and other ground object will change on the different bands. For instance on TM image's seven bands, water have the highest reflect rate on the 5-th band, so the spectrum value of water on the band is the largest, and on the near infrared band, water have the highest absorbency on this band and the spectrum value of water near to zeros ( $\mathrm{Li}$ et al., 2011).

The Normalized Difference Water Index (NDWI) was first proposed by McFeeters in 1996 to detect surface waters in wetland environments and to allow for the measurement of surface water extent (McFeeters, 1996). The NDWI is calculated using equation (1):

$$
N D W I=\frac{\text { Green }-N I R}{\text { Green }+N I R} \quad \text { Equation } 1
$$

Values of NDWI greater than zero are assumed to represent water surfaces, while values less than, or equal, to zero are assumed to be non-water surfaces. The enhanced water information using the NDWI is often mixed with built-up land noise and the area of extracted water is thus overestimated. Accordingly, the normalized difference water index (NDWI) was modified by substitution of a middle infrared band such as Landsat TM band 5 for the near infrared band used in the NDWI (Xu, 2006). The modified NDWI (MNDWI), equation (2), can enhance open water features while efficiently suppressing and even removing built-up land noise as well as vegetation and soil noise.

$$
M N D W I=\frac{\text { Green }-M I R}{\text { Green }+M I R} \quad \text { Equation } 2
$$

The NDVI is successful in predicting photosynthetic activity, because this vegetation index includes both near infrared and red light (Govaerts and Verhulst, 2010). The NDVI is calculated from reflectance measurements in the red and near infrared (NIR) portion of the spectrum as shown in equation (3)

$$
N D V I=\frac{N I R-\operatorname{Re} d}{N I R+\operatorname{Re} d} \quad \text { Equation } 3
$$

All the above indices were normalized in the range of $[-1,1]$, and zero was chosen as the threshold to distinguish water from vegetation and ground. However, because of the complexity 
of natural environment, different ground objects would have the same spectrum characters ( $\mathrm{Li}$ et al., 2011). Only one kind of index couldn't extract water body effectively from any kind of circumstance rather one kind of index method could only extract water bodies under some conditions instead of everyone.

For this study, the MNDWI is found to have good results except for the year 2015 which was better extracted using NDVI. Hence, the open water surface extraction was done using MNDWI and the year 2015 is eliminated from analysis at it is not well enhanced with the selected index.

\section{RESULTS AND DISCUSSION}

MNDWI index was run in Erdas Imagine in order to detect the lake water surface area from the 1985 to 2016 and comparison of the result with available literatures and Google earth image was done to check the reliability of the results.

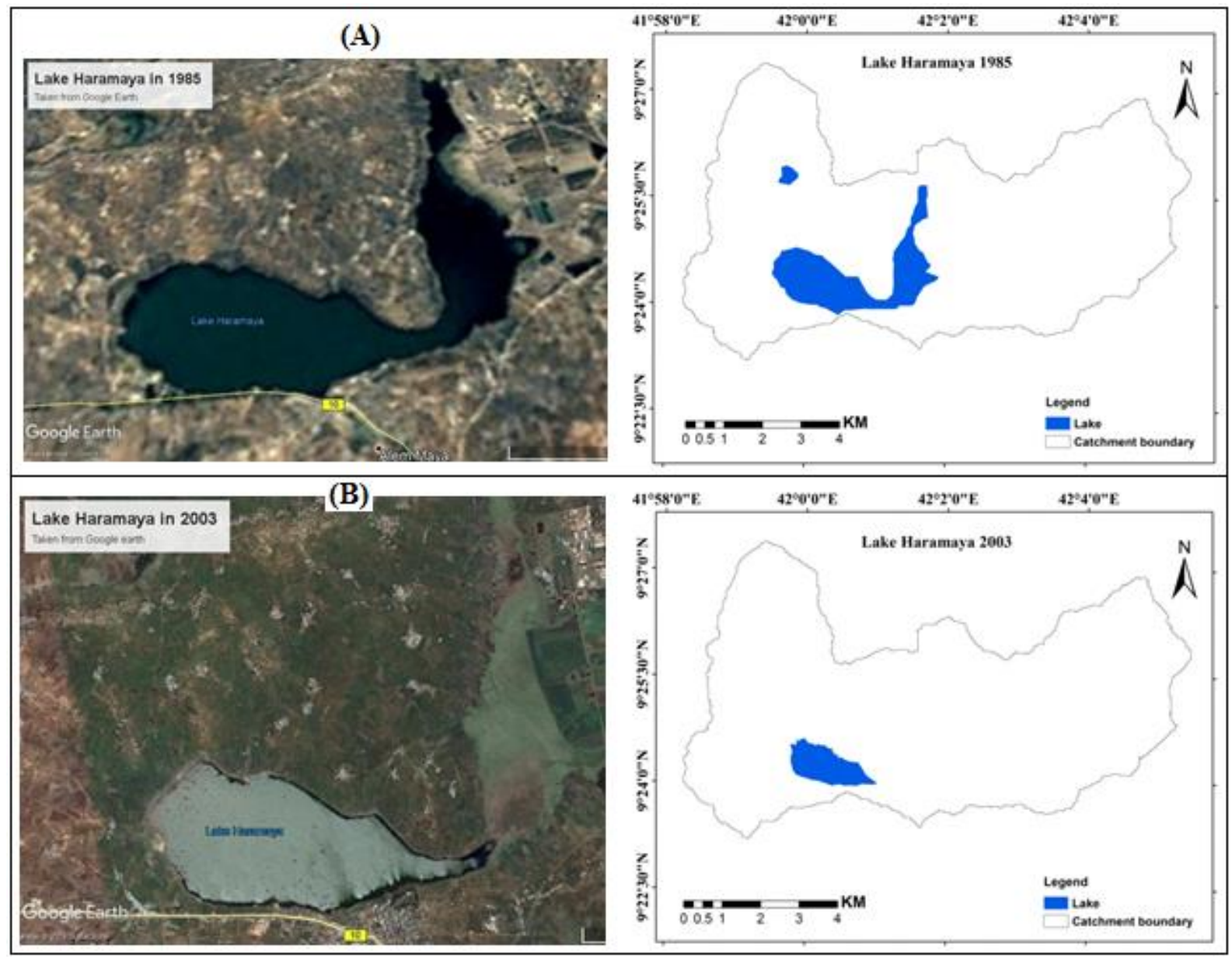

Figure 2. Comparison of result of MNDW with Google Earth images for 1985 (A) \& 2003 (B). 
As shown in figure 2, the index result is well aligned with Google Earth image of the years 1985 and 2003. Hence, MNDWI was employed to enhance and extract information with regard to the lake water surface area fluctuations. Figure 3 shows the enhanced lake water surface area for different years.

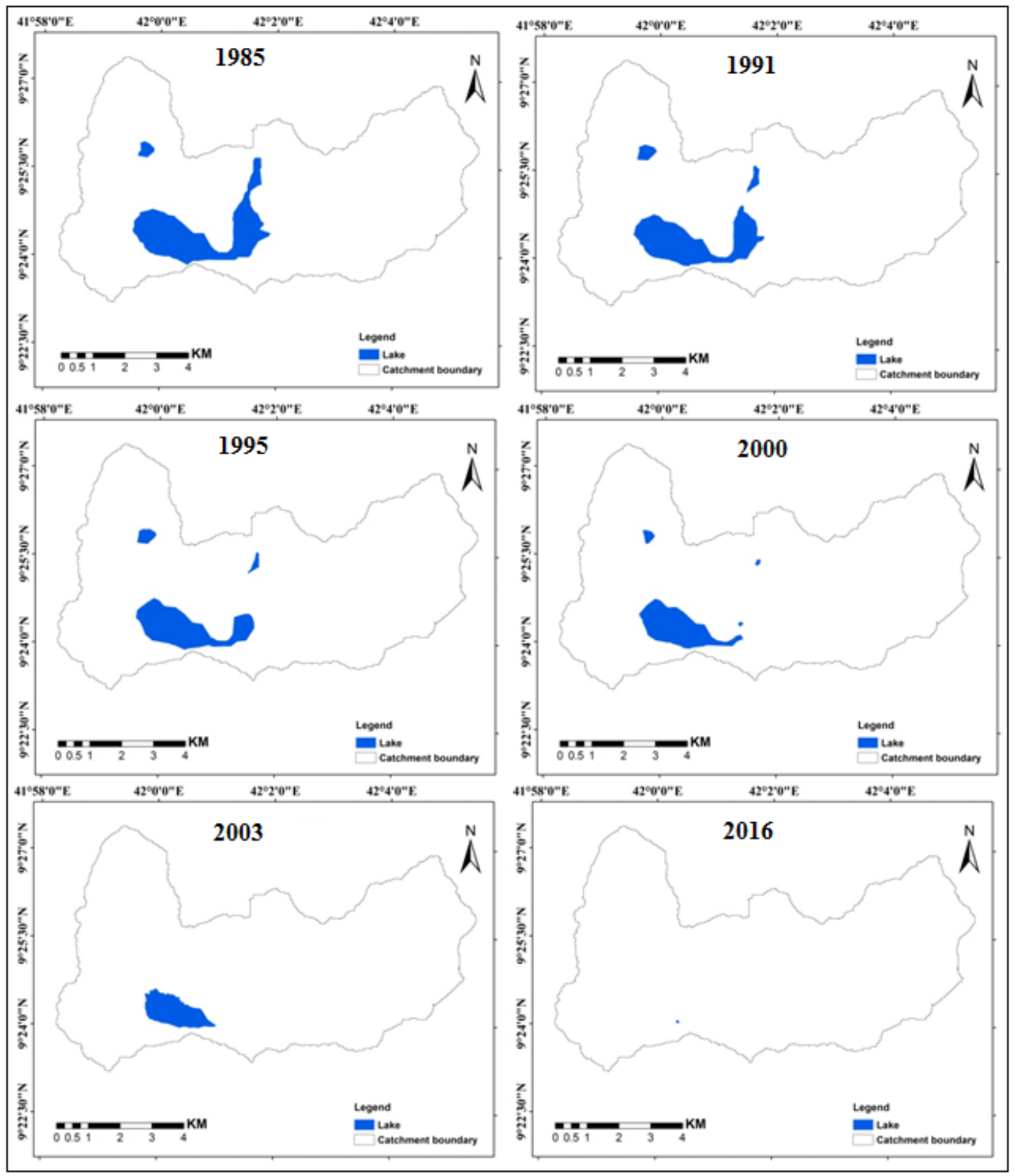

Figure 3. Enhanced surface area of Lake Haramaya over the years 1985 to 2016. 
As shown in figure 3, all of the enhanced images display a trend of decreasing lake surface water area from 1985 up until 2016. This result is in general agreement with our understanding about the history of the lake and documented in many literatures. For instance, Muleta et al. (2006) reported that the coverage of open water in the catchment was constantly declining over the period from 1965 to 1996 due to sedimentation of the eroded material from the catchment. Lemma (2011) argued that human demographic and climatic changes had contributed to the transformation of Lake Haramaya to an ephemeral lake (marshy area). It is further indicated that the increase in population in Harar town and in the lake watershed demanded high municipal water supply over the years that had never considered any water budget scheme.

The farmers in the watershed were pumping water out of the lake twenty-four hours a day to irrigate mainly commercial crops. Evaporation from the lake surface, then and now represents one of the major elements of the radiation and heat balance of the lake and its surroundings (Lemma, 2011). Evaporation is a major component of the lake water balance, but this variable is still difficult to estimate and has rarely been measured directly.

Over the study period the lake surface has shown a significant shrinkage by $16.7 \%, 18.4 \%$ and $23.5 \%$ between the years 1985 to 1991,1991 to 1995 and 1995 to 2000 . After 2000, the lake surface area shrinkage was at its maximum and shown decline of 35.7\% from year 2000 to 2003 .

Table 1. Lake area coverage and its shrinkage in percent over time.

\begin{tabular}{|ccccc|}
\hline \multirow{2}{*}{$\begin{array}{l}\text { Year } \\
(G \boldsymbol{C})\end{array}$} & \multicolumn{2}{c}{ Lake area } & \% shrinkage & $\begin{array}{l}\text { Average annual lake } \\
\text { area reduction (\%) }\end{array}$ \\
\cline { 2 - 3 } & $(\boldsymbol{h a})$ & $(\boldsymbol{\%})$ & & - \\
\hline 1985 & 467.46 & 7.79 & - & 2.8 \\
\hline 1991 & 389.25 & 6.49 & 16.73 & 4.6 \\
\hline 1995 & 317.76 & 5.30 & 18.37 & 4.7 \\
\hline 2000 & 243.05 & 4.05 & 23.51 & 11.9 \\
\hline 2003 & 156.20 & 2.60 & 35.73 & \\
\hline
\end{tabular}

From table 1, it can be inferred that the annual average lake surface area decline was $2.8 \%, 4.6 \%$ and $4.7 \%$ from the year 1985 to 1991,1991 to 1995 and 1995 to 2000 . The average shrinkage of the lake between the year 1985 and 2003 is about 23.6\%. According to Muleta et al. (2006), the lake decreased by an average value of $28.5 \%$ between 1965 and 1996 which is not contrasting with the results obtained in this study. 
Surprisingly, the decline over the period between 2000 and 2003 was $11.9 \%$ which is higher by more than twofold of the average declines before the year 2000.This indicates that the disappearance of the lake was exacerbated after 2000 which ultimately resulted to its complete disappearance few years later. In addition to the human intervention, the high shrinkage was also as a result of weather variability. As shown in figure 5, between the years 1999 and 2005 there had been a sharp increase in the average monthly temperature and a considerable decline in the total annual rainfall which can lead to higher evaporation and less recharge to the catchment water resources.

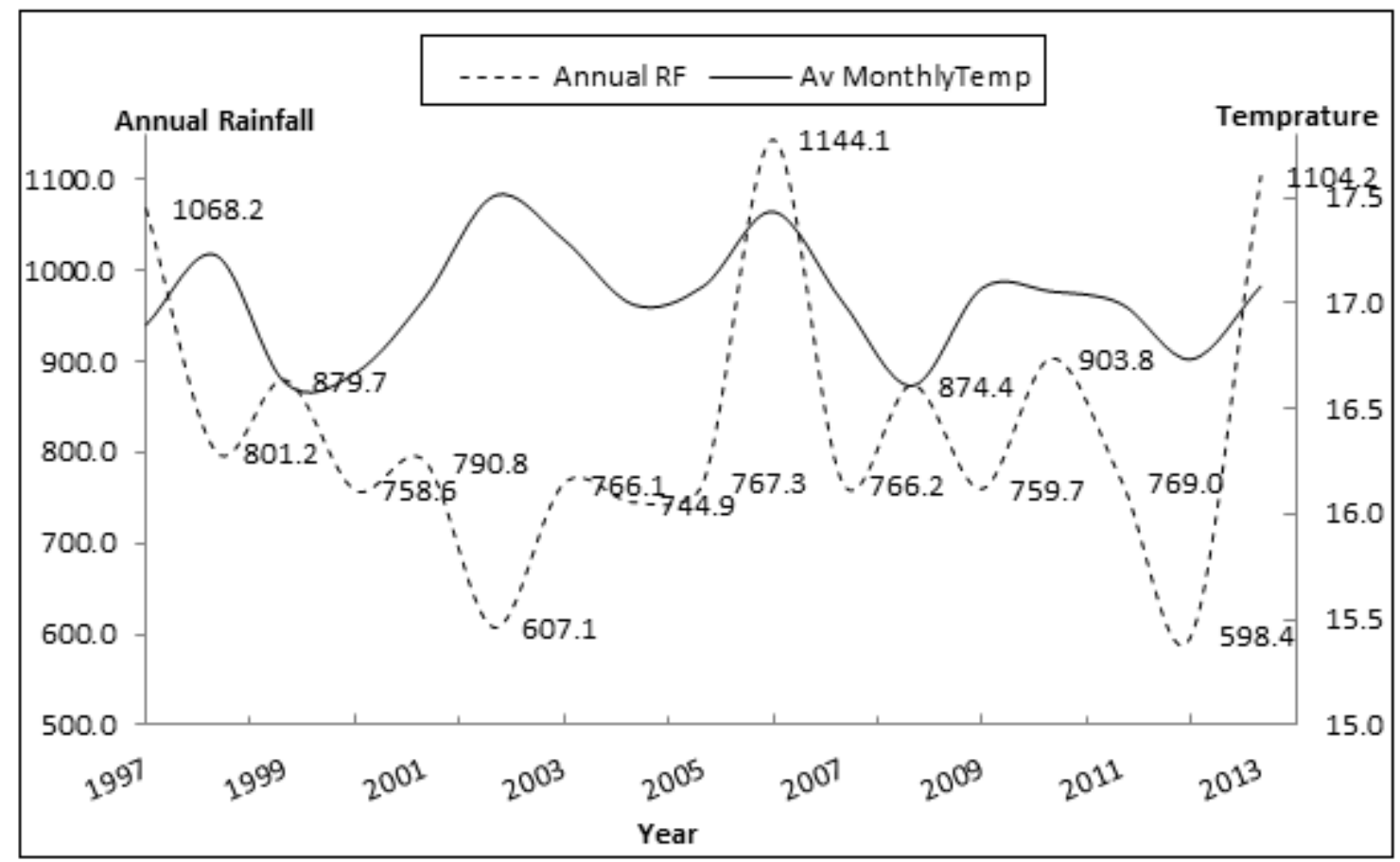

Figure 4. Temperature and Rainfall conditions on Lake Haramaya Catchment.

According to Assen (2011) the lake was dried-out completely in 2007. Nonetheless, Lemma (2011); and Furi (2005) indicated that the Haramaya Lake dried out some times at end of 2004 and beginning of 2004, respectively. However, as shown in table 1, 2.6\% of the catchment area was covered by lake in 2003 and it is not practical to get all this water disappeared with just a year. Hence, the conclusion by Assen (2011) is found more promising and the year 2007 is considered as the year when the lake was completely dried. The extinction of the lake has resulted in the evolution of marshy areas. According to Assen (2011) no marsh was observed in the years between 1965 and 1996. Nonetheless, in 2007 the marshy area covered 421 ha (3.05\%) 
of the watershed indicating an increase by $100 \%$; transformation of the lake into marsh area, ultimately this may convert to aquatic vegetation, which in the end may be converted to grassland, cultivated and urban/rural settlement land.

Comparison of the lake surface area is given in figure 6. The small lake surface area $(0.69$ ha) shown for the year 2016 is not a real lake. It is a pond dug into the dried lake by the community for the purpose of irrigation. From field observation, it was confirmed that there are plenty of hand dug wells excavated for irrigation purpose throughout the catchment area with significant numbers already on the dried lake area.

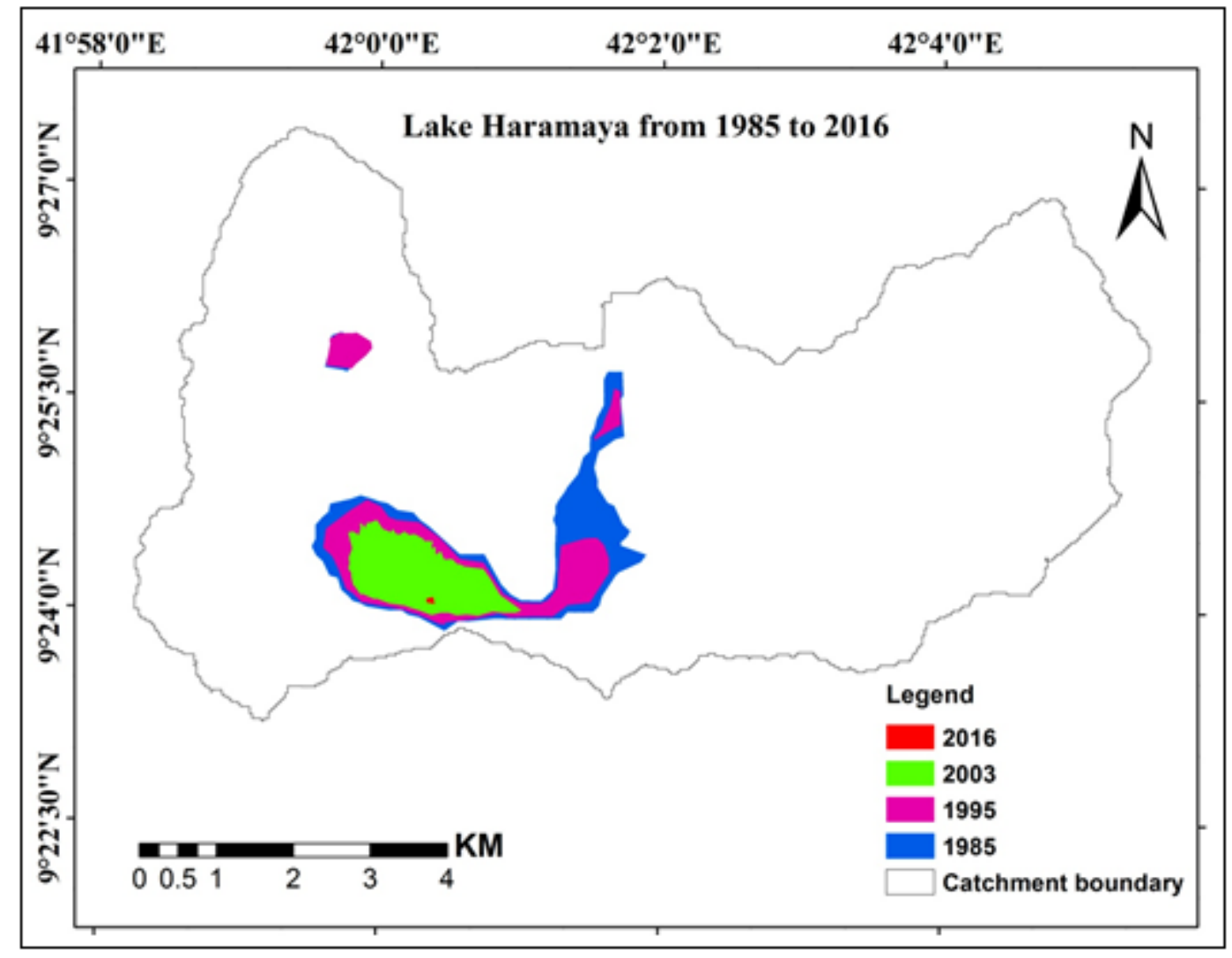

Figure 5. Comparison of Lake Water surface area in different years.

\section{CONCLUSION}

The Modified Normalized Difference Water Index (MNDWI) and Normalized Difference Vegetation Index (NDVI) performed better in enhancing and detecting open water surface of Haramaya Lake. The open water surface area of Lake Haramaya has shrunk by 16.7\%, 18.4\% and $23.5 \%$ between the years 1985 to 1991,1991 to 1995 and 1995 to 2000 . A high temperature 
increase and considerable reduction in rainfall was also observed from the year 1999 to 2005 which might facilitate the drying of the lake as a result of higher open water evaporation and less groundwater recharge. The disappearance of the lake was, therefore, attributed to climate or weather variability in addition to the human intervention.

\section{ACKNOWLEDGMENTS}

This manuscript is part of the project entitled "Rehabilitation of the Dry Haramaya Lake Basin and Efficient Utilization of Its Groundwater" funded by the Haramaya University Office of Research Affairs under the project code HURG-2014-01-03. Hence, special thanks goes to Haramaya University Office of Research Affairs for funding the project and article preparation.

\section{REFERENCE}

Alemayehu, T., Furi, W \& Legesse, D. 2007. Impact of water overexploitation on highland lakes of eastern Ethiopia. Environmental Geology, 52: 147-154.

Assen, M. 2011. Land use/cover dynamics and its implications in the dried Lake Alemaya watershed, eastern Ethiopia. J. Sustain. Dev. Africa, 13: 267-284.

Edo, B. 2009. Lake Haramaya Watershed Delineation and Groundwater Recharge Estimation Using Chloride Mass Balance Method. Master of science, Haramaya University.

Furi, W. 2005. Ground water productivity and the hydrology of the dry lakes basin in the north central sector of east Hararghe zone. MSc. thesis, Addis Ababa University, Addis Ababa, Ethiopia (unpubl.).

Govaerts, B \& Verhulst, N. 2010. The normalized difference vegetation index (NDVI) GreenSeeker ${ }^{\mathrm{TM}}$ handheld sensor: Toward the integrated evaluation of crop management. Part A: Concepts and case studies. Mexico, D.F.; CIMMYT.

Lemma, B., 2011. The impact of climate change and population increase on Lakes Haramaya and Hora-Kilole, Ethiopia (1986-2006): In Brook Lemma and Abebe Getahun (eds). Impacts of climate change and population on tropical aquatic resources. In: Proceedings of the Third International Conference of the Ethiopian Fisheries and Aquatic Sciences Association (EFASA), AAU Printing Press, Addis Ababa.

Li, M., Xu, L \& Tang, M. 2011. An extraction method for water body of remote sensing image based on oscillatory network. Journal of Multimedia, 6: 252-260. 
Mcfeeters, S. 1996. The use of the Normalized Difference Water Index (NDWI) in the delineation of open water features. International Journal of Remote Sensing, 17: 14251432.

Muleta, S., Yohannes, F \& Rashid, S. 2006. Soil erosion assessment of Lake Alemaya catchment, Ethiopia. Land Degradation \& Development, 17: 333-341.

Senti, E. T., Tufa, B. W. \& Gebrehiwot, K. A. 2014. Soil erosion, sediment yield and conservation practices assessment on Lake Haramaya Catchment. World Journal of Agricultural Sciences, 2: 186-193.

Setegn, S., Chowdary, V. M., Mal, B. C., Yohannes, F \& Kono, Y. 2011. Water Balance Study and Irrigation Strategies for Sustainable Management of a Tropical Ethiopian Lake: A Case Study of Lake Alemaya. Water Resources Management, 25: 2081-2107.

Tadesse, N. \& Abdulaziz, M. 2009. Water Balance of Haromaya Watershed, Oromiya Region, Eastern Ethiopia. International Journal of Earth Science and Engineering, 2: 484-498.

Tadesse, N., Bheemalingeswara, K. \& Abdulaziz, M. 2010. Hydrogeological Investigation and Groundwater Potential Assessment in Haromaya Watershed, Eastern Ethiopia. Momona Ethiopian Journal of Science, 2(1): 26-48.

Xu, H. 2006. Modification of normalised difference water index (NDWI) to enhance open water features in remotely sensed imagery. International Journal of Remote Sensing, 27: 30253033. 